\title{
Proceeding
}

Supplementary Issue: Summer Conferences of Sports Science. First International Conference in Iraq on Sport for Peace, 4 April 2019. Baghdad Science Institute, Baghdad, Iraq.

\section{Self-reflection technologies to design the developmental environment for the professional formation of sports teachers}

\author{
NATALIA B. KOVALEVA ${ }^{1} \triangle$, KIRILL S. EZHOV², OXANA E. CHERNOVA ${ }^{3}$, MIKHAIL G. LEONTEV ${ }^{4}$, \\ SVETLANA N. KAZAKOVA 5 \\ ${ }^{1}$ Department of Psychological Anthropology, Moscow State Pedagogical University, Moscow, Russia \\ ${ }^{2}$ Department of Physical Education and Sports, Ural State University of Economics, Yekaterinburg, Russia \\ ${ }^{3}$ Academy of Engineering, RUDN University, Moscow, Russia \\ ${ }^{4}$ Department of Social, Psychological and Legal Communications, National Research Moscow State University of Civil \\ Engineering (NRU MGSU), Moscow, Russia \\ ${ }^{5}$ Department of Nursing Activities and Social Work, The Sechenov First Moscow State Medical University, Moscow, \\ Russia
}

\begin{abstract}
The significance of this article lies in the fact that the problem of modifying the forms, methods and means of implementing the content of education, training and retraining of personnel for the sphere of physical education, sports and tourism always comes first among other pedagogical problems. To improve the educational process and, specifically, educational activities is an essential objective of all the system of education. The article presents the results of a study of the role, place and function of self-reflection in educational activities, as well as in the formation of a sports teacher's professional thinking based on self-reflective culture of solving professional problems. Based on the logical-substantive analysis, the article shows that the mechanism of self-reflective thinking is mandatory for the formation of the methodological culture of future specialists' professional thinking in the implementation of the curriculum content of physical education universities; it has been proved that activation of self-reflection during training leads to the fact that the learner makes his own activity as the object of his influence, he begins to purposefully change, improve or rebuild it. In addition, the article substantiates that the modern practice of education, training and retraining of personnel for the field of physical education, sports and tourism requires constant creative improvement of the teaching staff of higher education, which provides solutions to modern educational problems, the resolution of which will prepare competitive specialists for the open labour market; the analysis of a great number of scientific literature sources shows that psych didactics of developmental education should be based on activation of self-reflection, as a special way and means of forming self-reflective culture of sports teachers; the introduction of self-reflection in the educational process determines the improvement of the methodological culture and the personal inclusion of students, which undoubtedly leads to an increase in their professional competence. Keywords: Concept of developmental education; Self-reflection; Creative thinking; Professional activity; Pedagogy and psychology of higher education.

\section{Cite this article as:}

Kovaleva, N.B., Ezhov, K.S., Chernova, O.E., Leontev, M.G., \& Kazakova, S.N. (2019). Self-reflection technologies to design the developmental environment for the professional formation of sports teachers. Journal of Human Sport and Exercise, 14(5proc), S2103-S2115. doi:https://doi.org/10.14198/ihse.2019.14.Proc5.31

Corresponding author. Department of Psychological Anthropology, Moscow State Pedagogical University, Moscow, Russia. E-mail: nkovaig@mail.ru

Supplementary Issue: Summer Conferences of Sports Science. First International Conference in Iraq on Sport for Peace, 4 April 2019. Baghdad Science Institute, Baghdad, Iraq.

JOURNAL OF HUMAN SPORT \& EXERCISE ISSN 1988-5202

(c) Faculty of Education. University of Alicante

doi:10.14198/jhse.2019.14.Proc5.31
\end{abstract}




\section{INTRODUCTION}

The importance of this study lies in the fact that the problem of modifying the forms, methods and means of implementing the content of education, training and retraining of personnel for the sphere of physical education, sports and tourism always comes first among other pedagogical problems. It is no longer possible to improve the educational process and, specifically, educational activity by trial and error, and it turns out to be economically ineffective. The socio-economic situation in our country is such that in the structure of the dynamic processes taking place in our society, higher education has proved to be the most conservative. Didactics of developmental teaching and learning is designed to ensure the mental development of students through a specially organized system of pedagogical influence (Alekseyev, 1983; Davydov et al, 1990; Kovaleva, 2016a; Markova et al, 1990; Leontev, 2017). By concentrating on the practical implementation of the developmental learning principles, a positive effect can be achieved when the development of educational material does not occur through mechanical memorization, repetition, and reproduction, but through the students' mastery of generalized ways of thinking. Only in this case can we speak of development as the acquisition by an individual of socially developed methods of human activity and the transformation of these methods into forms of individual subjectivity (Slobodchikov \& Isaev, 1995). It is the acquisition of meaningfully generalized methods of activity that leads to the emergence of qualitative changes in the mentality of the student, the formation of new mental functions and the corresponding new constructs (Vygotsky, 1991). It is possible to achieve this task if, during the design and development of organizational forms and methods of developmental learning, the educational activity itself becomes the subject of self-reflection and analysis on the part of the student. Students are required to carry out a special kind of mental work in relation to the activity of mastering the patterns of activity transferred to them in training. This kind of work is a reflective analysis of one's own learning activities. Self-reflective and substantive analysis, revealing the contradiction between the form and content of joint activities, overcomes the limitations of individual actions. Due to this, the integrity of the activity and the awareness of its necessity by all participants are achieved, and therefore, the conditions are created for the development of the initially given patterns of joint educational activity. The goal of our study, presented in the article, was to determine the role, place and function of self-reflection in educational activities, as well as in the formation of professional thinking of a sports teacher based on the reflective culture of solving professional problems. The object of the study was the process of education, training and retraining of a physical education and sports teacher. The subject of the study consisted in investigating the structure and content of the methods and means that can help to form self-reflective culture of sports teachers. The objectives of the study were the following:

1. To conduct a logical and meaningful analysis of the structure and content of educational activities at universities teaching physical education and sports.

2. To identify the importance of self-reflection in the formation of active cognitive thinking activity in students.

3. To experimentally substantiate the most significant components of self-reflection, which form the basis of psychological and pedagogical technology for the formation of self-reflective culture of a sports teacher?

As a result of the conducted study, it was proved that the modern practice of education, training and retraining of personnel for the field of physical education, sports and tourism requires constant creative improvement of the teaching staff working in the field of higher education, which provides solutions to modern educational problems, the resolution of which will make it possible to train competitive specialists for the open labour market. An analysis of a great number of scientific literature sources shows that psych didactics of developmental education should be based on the activation of self-reflection, as a special way and means of forming self-reflective culture of sports teachers; the introduction of self-reflection in the educational process 
determines an increase in the methodological culture of students, their subjectivity and personal involvement in the process, which undoubtedly leads to an increase in their professional competence and social maturity (Alekseyev , 2002; Kovaleva \& Kovalev, 2018, Ponomarev \& Semenov, 1990; Zaretsky, 2014). The theoretical significance of the research results is determined, firstly, by the development of the content of the mechanism of self-reflective thinking in the organization of educational activities at universities majoring in physical education; secondly, by highlighting the most significant components of self-reflection, which form the basis of pedagogical technology for the formation of self-reflective culture of a sports teacher; thirdly, by highlighting the structure of contradictions, the self-reflective analysis of which contributes to the improvement of the content of educational activities, which, in turn, significantly improves the methodological culture of both teachers and students. The practical significance of the results of our study consists in developing the structure and content of the mechanism for the formation of self-reflective culture of a sports teacher. The obtained data can be used to design a special course for teaching students, training specialists, retraining personnel for the field of physical education, sports and tourism in continuing education institutions, schools of higher sports skills for coaches.

\section{METHODOLOGICAL FRAMEWORK}

The radical transformations of the country's cultural and socio-economic life have led to the emergence of new values in education, and have formed stable demands in society for a professionally competent teacher who is capable of providing an environment of developmental education and creating the psychological and pedagogical conditions for effective education and upbringing of people. One of the functions of higher education is the transformation of society through the development of independence and creative potential of students. Such an educational system requires a professional teacher, who is a genuine subject of pedagogical activity, focused on the development of the abilities and personality of students, and not just on the dissemination of knowledge, skills; who is able to construct developmental educational situations, and not just set and solve didactic tasks. This should be a teacher of a new type, able to quickly respond to ongoing social changes, adjust his own professional activities in accordance with changing social requirements. A characteristic feature of his professional consciousness should be the concentration of thinking on pedagogical problems, the vision of the pedagogical process as an integral phenomenon, the central place in which belongs to the student's developing personality (Kovaleva, 2017; Nesterova et al., 2019; Ponomarev \& Semenov, 1990; Lomakina, 2015). A sports teacher should have a whole range of qualities, without which the implementation of the abovementioned tasks will become almost impossible. An orientation toward self-education, self-development, self-knowledge; the need and capability for selfreflection of pedagogical activity is necessary for the professional growth of these teachers. In the activity of a sports teacher, self-reflection plays a decisive role, since it focuses on self-analysis of the results of his own work, a comprehensive analysis of behaviour of all participants in the educational process, interpersonal relationships, as well as on the correction of interaction between them. In addition, self-reflection acts as one of the main mechanisms for the realization of human activity, its self-development, and targeted reflective interaction between the teacher and students can be the basis for successful management of educational and professional activities (Miroshkin et al., 2019; Salakhova et al., 2016a; Salakhova et al., 2018b). Selfreflection means awareness of oneself and the expectations of other subjects of the educational process; this is an attempt to understand what is happening in oneself and oneself in what is happening through independent appeal to introspection (Markova et al, 1990; Salakhova et al., 2016b; Vulfov \& Kharkin, 1995). Professional self-reflection provides a willingness to act in situations with a high degree of uncertainty, flexibility in decision making, the desire to implement innovations, a constant focus on finding new, innovative ways to solve professional problems, and the ability to rethink the stereotypes of one's professional and personal experience (Borytko, 2007; Mitina et al., 2017; Salakhova et al., 2019). Pedagogical self-reflection 
is defined as the teacher's consciousness focused on himself, taking into account the students' ideas about his activities and how the teacher understands the student's activities. It is directed towards the teacher's self-organization through understanding of himself, his professional activity as a way to implement his holistic "l" and is effective to the extent that the subject is able to understand, accept, promote the actions of others (Chernilevsky, 2003). In the ontological aspect, psychological and pedagogical reflection acts as a means of establishing the human world in the profession (transformation of the value-meaning components of the image of the profession and a professional as a determinant of the formation of the image / style of professional activity and communication), since it is aimed at fixing the subject of current and final changes (achievements), as well as forecasting the course of formation of professional competence. To a varying degree, pedagogical self-reflection is inherent in any teacher (Dana \& Sabzi, 2013). For instance, the ability to think and act unconventionally is always clearly present in innovative teachers' creativity. The analysis of their activities shows that they highly tend to show self-reflection (analysis) of their own pedagogical experience. It is it that makes it possible to improve the empathic aspect of pedagogical mastery - the ability to take the position of a student and look at oneself from it and at the situation as a whole. Pedagogical selfreflection is the most significant quality of the personality of a sports teacher, ensuring the growth of professionalism of the teacher and his way of becoming a professional, the formation of his personal position. In this regard, its formation and development in the process of training is an important task of the higher education system (Kalenik et al., 2018; Kovaleva, 2017; Masalimova et al., 2019; Salakhova et al., 2016c; Salakhova et al., 2018a; Sokolovskaya et al., 2019). Pedagogical self-reflection is realized in reflective activity, combining analytical, evaluative and sense-searching activity in single meta-activity. The forms of its manifestation in practice are: psychological and pedagogical diagnostics, research, design and project work. These activities are extremely important for a sports teacher. Self-reflection is the basis of the teacher's activities at all its stages: from a concept to obtaining and analysing results. This can be represented in the form of the following chain: the purpose of pedagogical activity - a reflective analysis of the situation - choice; design and construction of means of pedagogical activity by the teacher on the basis of self-reflection on the adequacy of these means to the goal (plan) - project implementation -self-reflection on the distinction between the project and its implementation (goal and result) (Alekseyev, 2002; Erofeeva et al., 2019; Kalinina et al., 2018; Leontev, 2016; Slobodchikov \& Isaev, 1995; Kovaleva, 2014). At the same time, the teacher's self-reflection can be directed to the subject of pedagogical activity, to pedagogical activity itself, to interaction with other people, to identifying one's own means and ways of thinking, understanding, communication, as well as actions and activities of students, understanding their ways of working, thinking, communication. In the implementation of the teacher's self-reflection in physical education and sports, one can identify the following interrelated points: the teacher's awareness of the true motives of his pedagogical activity; the ability to distinguish own difficulties and problems from difficulties and problems of students; the ability to empathy and decentration; the ability to see yourself through the eyes of a student. The main structural elements of the process that determine the development of pedagogical reflection are: diagnostics of the state of both the development process itself and its results, the level of development of pedagogical reflection; correction of the learning process of self-reflection; the problematic research nature of training. In addition, in the context of our study, it is important to understand the key functions of self-reflection, which include the following: creative (manifested in creating conditions for the development of the student's creative potential); reflection itself (allows him, first of all, to rethink his previous experience); stimulating (involves creating conditions for the manifestation and development of reflective activity), prospective (projects the image of the future), subjective and personal (carries out the process of paying attention to oneself) (Babieva et al., 2019; Grinenko et al., 2019; Kovaleva, 2014; Zaretsky, 2014). In view of the aforesaid, the general criteria for the effectiveness of the pedagogical reflection development process are: strengthening positive motivation for professional-personal self-knowledge, self-regulation and self-development; the development of the teacher's meaningful attitude to himself and his future professional activities; raising the level of pedagogical 
self-reflection; technological character of the reflective activity process (completeness, consistency, sciencebased approach, etc.). A substantial analysis of reflective activity as a specific type of mental activity suggests that activation of reflection during training leads to the fact that the student makes his own activity as the object of his influence, he begins to purposefully change, improve or rebuild it. And in this sense, the achievement of the goal of mental development is in contact with the processes of self-development and selfchange (Alekseyev, 1983; Kovaleva, 2015a; Kovaleva, 2018; Ponomarev \& Semenov, 1990; Rastiannikov, Stepanov \& Ushakov, 2002; Semenov, 2017; Vulfov \& Kharkin, 1995). The development, guided and organized by the teacher, goes to self-development, the student himself becomes its driving force. The catalyst for the development of a culture of self-reflection and the development of subjectivity is also the reflective-positional co-organization of the processes of communication, cooperation and joint activities of students (Kovaleva, 2015; Kovaleva, 2016a, 2016b; Leontev, 2018; Rastiannikov, Stepanov \& Ushakov, 2002; Zaretsky, 2014). This is how true development occurs during training, as a result of which the learner becomes independent from the teacher, having added mental ways and means of education and selfeducation to himself. As a result of the theoretical analysis, we have identified and formulated the main characteristic features of professional thinking in the field of physical culture and sports, which can be formulated to a certain extent when studying the subject of pedagogy:

1) Good command of methodological knowledge and means of solving problems,

2) An understanding of the scientific knowledge structure,

3) Knowledge of the aspect problems of pedagogy and psychology and command of generalized methods for solving them,

4) awareness of the cognitive cycle structure and the ability to carry out creative procedures at each stage (to pose a problem, put forward hypotheses, derive consequences, determine means of solving problems, etc.),

5) The ability to carry out procedures of describing, explaining, deriving prescriptions,

6) The ability to consider phenomena and processes in the field of physical culture and sports in interconnection and development,

7) The ability to carry out cognitive activity both in a team and independently.

The results of the study confirm the features of human reflective thinking already accumulated by other researchers, which allow us to formulate some general principles for devising curricula, the content of which corresponds to the goals of forming the basics of theoretical thinking in students of physical culture universities. We will highlight some of these principles:

- All the concepts constituting a given subject or its main sections should be assimilated by students through considering such conditions of their origin, due to which they become necessary,

- Mastering knowledge of a general and abstract character is preceded by the acquaintance with more private and specific knowledge, the latter should be derived from the abstract as from its own unified basis,

- When studying the subject sources of certain concepts, students should first of all discover the genetically original, essential, universal relationship that determines the content and structure of the entire object of these concepts,

- This relationship must be reproduced in subject, graphic or symbolic models that make it possible to study its properties in a "pure" form,

- One should form specifically such actions in students by which they can identify and model the essential relationships of the object in the educational material and then study their properties,

- Students must constantly and timely move from objective actions to their implementation in the mental aspect based on the formed self-reflective thinking culture. 


\section{MATERIALS AND METHODS}

An empirical study was conducted at Moscow State Pedagogical University. Students of the second and third years with the total number of 70 people as well as the teachers of the department of sports and adaptive activities (total number of 28 people) participated in the experiment. Active teaching methods were integrated for the experimental group of students in the educational process, in particular a reflective analysis of professional situations. Active teaching methods included: pedagogical games, discussions, research projects, psychological trainings, analysis of pedagogical situations, keeping a diary, and self-observation. At the end of the course, all students were questioned in a survey to determine the attitude of students to a reflective analysis of professional situations. The method of pedagogical games included the use of educational simulation and business games. Self-reflection is an element of a business game, usually containing several successive cycles. The transition from one cycle to another or termination of the process is carried out in accordance with the result of self-reflection undertaken after each cycle. At the same time, the content of the decisions made, the rules for their adoption and implementation can be revised and modified. By virtue of this, the business game contains self-reflection as a necessary element of selforganization and self-control. If it is impossible to solve a problem in the new conditions in a previously developed way, they formulate an auxiliary, mediating problem with respect to the original one, and include personal forms of reflection. Having solved the latter, they find the solution to the original one, the chain of such mediations can be quite long. Participation in games makes it possible, firstly, to diagnose possible professional difficulties, and secondly, to get involved in the process of professional self-development, development of one's pedagogical position. The most effective way to implement the method of educational games in order to create conditions for self-development of reflection is a change of position in the process of playing roles. Situations in which the role is combined with self-belief can have a profound effect on the personality, leading to significant changes. This method lies in the fact that it is necessary to actively accept the role of another person (character), for example, a teacher, in order to achieve adequacy in the perception and understanding of this person. Sometimes it is enough just to observe how another member of the group plays a role so that changes in perception and attitudes occur (Kovaleva, 2015b). Discussions also contribute to the development of reflective abilities. In our study, discussion topics were given in advance for self-study and preparation for discussion. During the discussion, the opinion of each participant was taken into account, which sometimes led to a clash of opposing views and initiated changes in one's own views and attitudes. Interpretation of various viewpoints, positions, behaviour during discussions helped to develop self-reflective abilities. By analysing the opinions and behaviour of people, trying to understand the causes of behaviour and the essence of thought, one can achieve a higher level of self-reflective culture (going beyond one's own consciousness). The ability to assess and hermeneutically interpret one's and other's positions, points of view, behaviour is a necessary quality of a contemporary teacher who combines the positions of a psychologist, a hermeneutist, a facilitator and an artist (Demakova, 2012; Kovaleva, 2016a). Engaging the audience in the process of the systematic analysis of a persuasive message and its problems, active and careful thinking generate knowledge that is easily remembered, well linked to each other. Thus, the information acquired in the process of discussion is retained better than the knowledge arising from passive learning. The use of special training courses to develop self-reflection enhances the motivation of professional education, professional activity for students, and promotes development in self-improvement. The main techniques of the training course are a chain of self-questions: "Why?", "What for?", "What is need?" "What is the problem?", "How to act, how to change the situation (oneself)?", "Is it necessary to change anything?" and similar questions, answering which, students not only begin to understand themselves better, but also determine the need (or lack thereof) for specific actions, conditions, identify the value basis of their choices, plan a self-development strategy. In terms of the process self-reflective training courses corresponded to the mechanisms of self-reflection and included the following stages: determination of the 
subject of self-reflection - professional choice, professional goals and values. They were also based on the use of (Alekseyev's, 2002) action scheme in a modified version: stopping the action - distraction from the questions that are not related to the subject of self-reflection); spotting - the primary identification of a contradiction, complexity or conflict, raising questions, focusing on oneself, one's thoughts, one's inner world, motives and interests, one's life experience; formulation of answers to questions; estrangement - emotional alienation from stereotypical ideas; an attitude to the search for new ideas or points of view, study and analysis of oneself "from the outside"; objectification - the analysis of one's actions, feelings, relationships, the search for objective grounds to understand the situation and cultural ways to solve the problem; turning around - a return to the initial situation, to the originally formulated answers, correlating them with new experience, with what is realized as a result of self-reflection; comparing one's goals, motives, interests and actions aimed at their achievement, implementation, satisfaction (Alekseyev, 2002; Kovaleva, 2015b). Diary records and self-questions also contribute to the development of self-reflection. If a person is able to adequately evaluate himself, critically and objectively assess his actions and deeds, then there is a need to form an attitude of successful professional activity that will contribute to mental awareness and selfimprovement of the personality as a whole (Akchurina \& Amyaga, 2015; Kovaleva, 2015). The results of the survey testify to the effectiveness of the proposed didactic methods related to the development of selfreflection skills in students. The survey embraced all 60 students included in the formative experiment.

\section{RESULTS AND DISCUSSION}

According to the results of the questionnaire, it was found that $97 \%$ of the students of the experimental group have a positive attitude to reflective analysis of professional situations as active teaching methods. Since the questions were half-closed, the students explained why their attitude to this form was positive. For example, in a business game, students pointed out business activity (25\%), emotional perception (25\%); in the discussion - gaining new knowledge about the profession (33.3) and communication with friends (25\%). In addition, students expressed suggestions about the need to conduct such classes not only during the formative experiment, but also in general when organizing all the educational activities to master the content of the training program, as well as during the process of reflective analysis, to give more time to prepare for reports, carry out preliminary preparation for this form of training. Thus, the results of the questionnaire indicate that the teaching of various disciplines must be carried out in the form of models of active cognitive educational activity, and such teaching, if carried out systematically, should help students develop the fundamentals of theoretical thinking and consciousness. Intellectual processes serve as the leading condition for their functioning and development in mental and objective activity, and reflection is scientifically explained as a principle and mechanism of thinking, understanding, reason, rationality, etc. The degree of development of intellectual processes, the measure of their rationality, directly characterize the reflective culture of the individual. The presence of a clear idea of the nature, structure and content of the reflective culture of a sports teacher requires an appeal to the process of modelling the phenomenon under study.

A rather compact system of ideas serves as a methodological basis to design a model of a sports teacher's self-reflective culture:

1) The philosophical and methodological concept of "culture", "professional pedagogical culture" and "self-reflection",

2) The systematic approach, requiring the consideration of self-reflective culture as an integral system of concepts and guiding its harmonious development,

3) The personality-oriented approach, from the position of which a person in the model of self-reflective culture acts as a phenomenon of its functioning and development, 
4) The culturological approach that allows one to consider self-reflective culture as a set of cultural components that characterizes a person as a cultural subject - an admirer and creator of cultural values.

Taking into account the indicated methodological bases makes it possible to substantiate the student's reflective culture model in logical-hierarchical figure 1 , and to distinguish the following specific components of the consciousness and self-consciousness of the future teacher's personality: value-meaning constructiveorganizational, meta-subject and project-creative.

Relationships of the components of a reflective culture in logical-hierarchical figure 1.

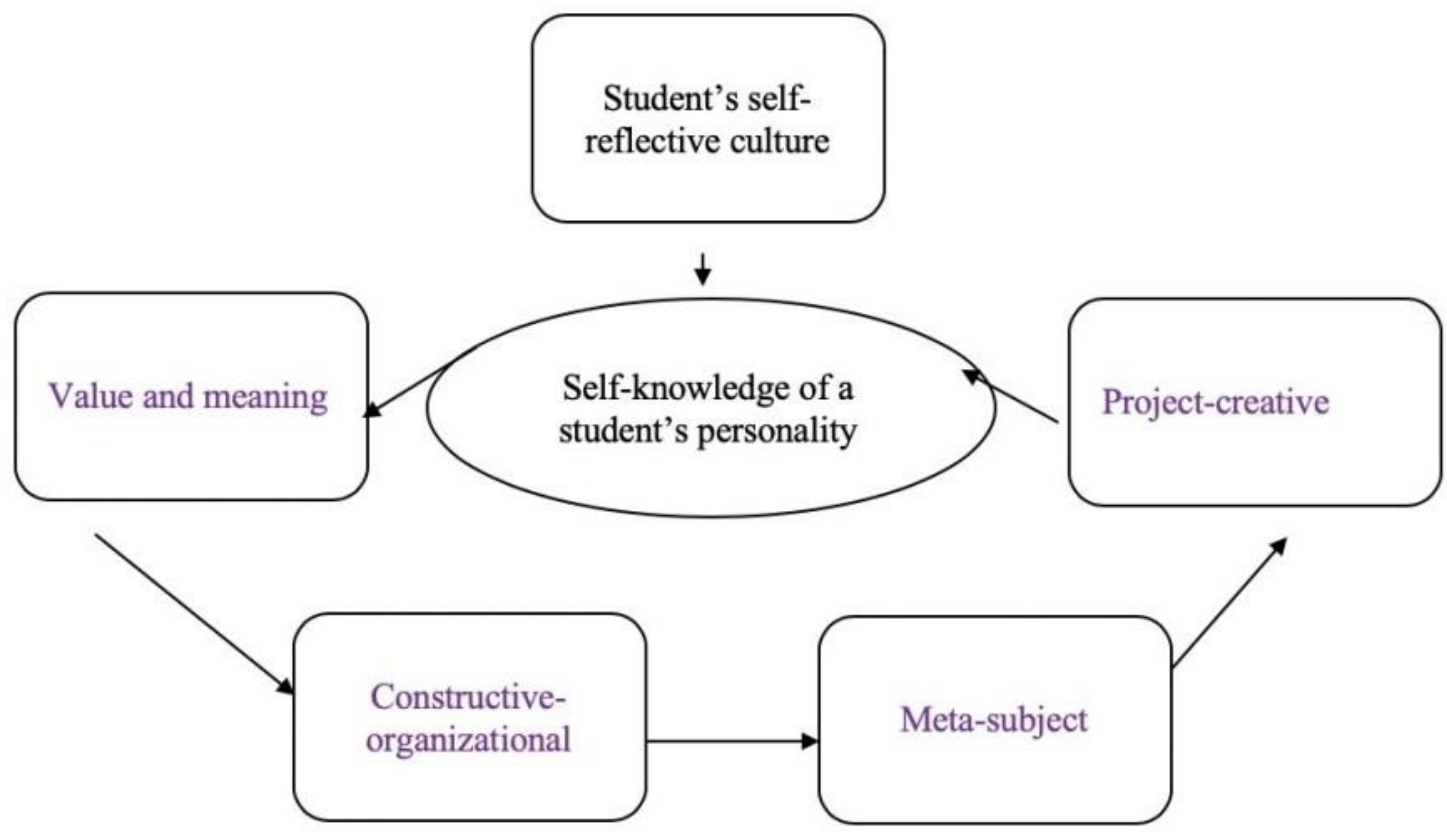

Figure 1. Self-reflective culture components of a sports teacher in their relationship with self-knowledge.

From the position of a systematic approach, this model includes four interconnected components that provide the process to manage the development of self-reflective culture among sports teachers, based on their criteria-based characteristics. The development level of structural and functional components of a sports teacher's self-reflective culture determines the degree of its development. Therefore, to conduct a study of the levels of formation of the future teacher's self-reflective culture, the identification of the parameters for assessing the studied phenomenon is of particular importance. It seems that in order to enhance selfreflection in students, the most acceptable form of training is the educational game (based on the results of the questionnaire), which can be successfully used to study the psychological functions of self-reflection. The structural and functional model of a self-analysis proposed above is taken as the basis; accordingly, certain attributes are assigned to each component of self-reflection, according to which a conclusion is made about their functioning. Let us consider the table (table. 1) of such manifestations, assuming that it bears a search character. 
Table 1. Components of self-reflection in educational activity.

\begin{tabular}{|c|c|}
\hline $\begin{array}{l}\text { Components } \\
\text { reflection }\end{array}$ & Signs and forms of manifestation \\
\hline $\begin{array}{l}\text { Value-meaning } \\
\text { component } \\
\text { (intention to master } \\
\text { one's own activity) }\end{array}$ & 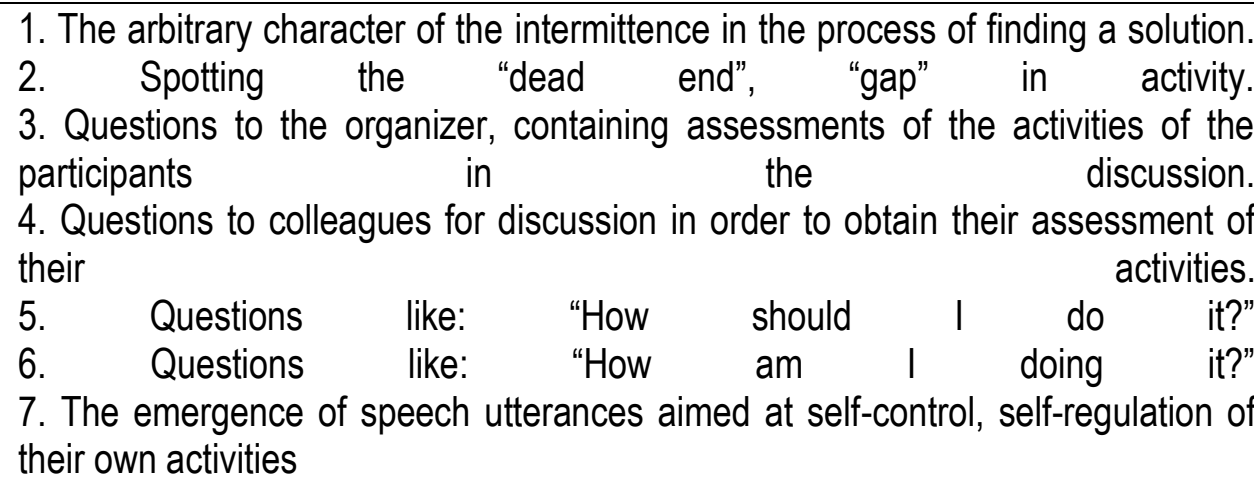 \\
\hline $\begin{array}{l}\text { Structural } \\
\text { organizational } \\
\text { component }\end{array}$ & $\begin{array}{l}\text { 1. The presence of uniformity of speech generation (for example, a participant in a } \\
\text { discussion concentrates his attention only on means of activity or on its conditions). } \\
\text { 2. The search for elements of activity, a self-reflective analysis of which will make } \\
\text { it possible to resolve a conflict situation. } \\
\text { 3. Categorical relevance and design of self-reflective elements of activity. } \\
\text { 4. The search for the functional place of the analysed element in the general } \\
\text { structure of activity. Establishing links of the reflected element with other elements } \\
\text { of activity } \\
\text { 5. The organization and co-organization of elements, relationships and relations of } \\
\text { activity is carried out with the updating of the schematization component }\end{array}$ \\
\hline $\begin{array}{l}\text { Meta-subject } \\
\text { component: } \\
\text { schematization } \\
\text { Estrangement and } \\
\text { objectification }\end{array}$ & $\begin{array}{l}\text { Schematization: } \\
\text { 1. Drawing schemes, various drawings, replacing one or another idea of one's own } \\
\text { activities or its alements. } \\
\text { 2. The use of the drawn diagrams in the process of finding a solution. } \\
\text { 3. The presence of minimized abbreviated speech, emphasizing only the essential } \\
\text { connections, elements and relations of activity. } \\
\text { 4. The presence of various forms of gestures, for example, movement of the hands, } \\
\text { imitating the strategy of their own advancement in solving the problem } \\
\text { Estrangement and objectification: } \\
\text { 1. The lack of emotions and feelings about the analysis of one's own activities. } \\
\text { 2. Features of impartiality analysis of one's own activities. } \\
\text { 3. Relation to oneself as a partner (for example, internal dialogue with oneself, an } \\
\text { argument } \\
\text { 4. Objective expression of thought }\end{array}$ \\
\hline $\begin{array}{l}\text { Project-creative } \\
\text { component }\end{array}$ & $\begin{array}{l}\text { 1. The presence of all the preceding components of self-reflection in certain forms } \\
\text { of manifestation and their introspective use use } \\
\text { 2. Getting non-standard, original and new ways to solve the problem. } \\
\text { 3. Identification and awareness of the moment of getting a new method of solution. } \\
\text { 4. The manifestation of the "effect" of surprise in the process of resolving problems } \\
\text { 5. Feeling of joy and desire to share the discovery }\end{array}$ \\
\hline
\end{tabular}

Based on the proposed methods for the formation of self-reflective culture and thinking, teachers of physical education universities can develop a structure of subject tasks, the development of which by students in specific forms of educational activity will lead to a more thorough development of the content of the subject 
under study and will also contribute to the understanding of the role and functions of this subject in the future holistic professional activity of a specialist. As a result of the conducted research presented in this article, it is possible to determine the requirements for the content and technology of the method of forming students' reflective thinking, which are implemented in educational activities by university teachers:

- All the concepts constituting the subject, or its main sections should be assimilated by students by considering such conditions of their origin, due to which they become necessary to solve a serious scientific and practical problem;

- When studying the subject sources of certain concepts, students should first of all discover the genetic, essential, universal connection that determines the content and structure of the entire object of these concepts;

- This relationship must be reproduced in subject, graphic and symbolic models, allowing one to study its properties in a "pure" form;

- Students should specifically formulate such actions through which they can identify and model the essential connections of objects in the educational material, and then study their properties and determine their cultural significance;

- It is important to constantly and timely switch from objective actions to performing them in a mental aspect;

- It is advisable to include as many creative and project tasks as possible, initiating creative inclusion based on the intensification of personal self-reflection;

- Students are recommended to actively participate in discussions and educational games that contribute to the development of their positions through group synergy.

\section{CONCLUSION}

Self-reflective culture is a complex cognitive action, the purpose of which is to form the unity of the universal, the special and the single. These actions are based on a single method, implemented through the acts of analysis and reflection, which have different contents depending on the purpose of a particular private action. The consistent mastery by man of reflective culture methods is a phased appropriation of the content of the theoretical thinking development. The ability not only to successfully solve a number of problems corresponding to situations of professional reality, but also to highlight the features and conditions for their successful and effective implementation serves as the criterion for the implementation of theoretical thinking with the use of the self-reflective method. The use of active forms of training, including simulation, role-playing plot-action games and reflective-positional discussions and trainings stimulates personal inclusion, the development of a professional position, the discovery of the value and cultural significance of education and the development of students' professional identity. Based on the proposed methods for the formation of selfreflective culture and thinking, physical education teachers at universities can create a structure of developing subject and meta-subject tasks, the meaningful development of which by students in specific forms of educational activity, will lead to a more thorough development of the content of the subject and will also contribute to the understanding of the role and the functions of this subject in the future holistic professional activity of a specialist.

\section{REFERENCES}

Akchurina, N.N. \& Amyaga N.V. (2015). Workshop on the FGOS transformation to educational programs of the initial, main and full general education. Moscow: GAOU MIOO Publ. 
Alekseyev, N.G. (1983). Reflection and consciousness. Categories, principles and methods psychologies. Psychophysical processes. Moscow: OP, USSR.

Alekseyev, N.G. (2002). Design and reflexive thinking. Development of the personality, 2, 92-115.

Babieva, N.S., Grinenko, A.V., Shulga, T.I., Tkhugo, M.M., Zotova, L.E., Shukshina, L.V. \& Ishkov, A.D. (2019). A psychological resource of personality as an integral eco-psychological characteristic (the interrelationship of personal development and quality of human life). Ekoloji, 28(107), 629-635.

Borytko, N.M. (2007). Experience in implementing a humanitarian approach in profile training. Creative pedagogy. Almaty, 1(30), 12-29.

Chernilevsky, D.V. (2003). Spiritual and moral values of the educational system of Russia of the XXI century. Moscow: RIO MGTA.

Davydov, B.B., Neverkovich S.D. \& Samoukina N.V. (1990). About the function of reflection in the game training of leaders. Questions of Psychology, 3, 19-25.

Demakova, I.D. (2012). Hermeneutic approach to the analysis of forms of cultural education (art) on sat scientific papers. Cultural forms of education: status and prospects. Moscow: Bank of cultural information.

Erofeeva, M.A., Grinenko, A.V., Stanovova, L.A., Kosolapova, N.V., Mikhaylovsky, M.N., Rybina, I.A. \& Kochetkov, I.G. (2019). Motivation and motives of juvenile delinquents. EurAsian Journal of BioSciences, 13, 1-6.

Dana, A, Sabzi, A.H. (2013). The Relationship between Religiosity and Athletic Aggression in Professional Athletes, UCT Journal of Social Sciences and Humanities Research, Issue 4,pp.01-05.

Grinenko, A.V., Gegel, L.A., Poleshchuk, I.A., Tutaeva, D.R., Pronina, E.V., Shchukina, T.V. \& Egorova, E.V. (2019). A governing and political orientation in the field of education. EurAsian Journal of BioSciences, 13, 1-6.

Kalenik, E.N., Salakhova, V.B., Mikhaylovsky, M.N., Zhelezniakova, M.E., Bulgakov, A.V. \& Oshchepkov, A.A. (2018). Psychophysiologic features and personal-adaptive potential of students with limited abilities. Electronic journal of general medicine, 15(6), em98. https://doi.org/10.29333/ejgm/100635

Kalinina, N.V., Zaretskiy, V.V., Salakhova, V.B., Artamonova, E.G., Efimova, O.I. \& Lekareva, E.E. (2018). Psychological and pedagogical resources of security provision and prevention of internet risks and life threats among children and teenagers in the educational environment. Modern journal of language teaching methods, 8(8), 118-129.

Kovaleva, N.B. \& Kovalev, F.A. (2018). Reflective-positional approach to the development of the personality and abilities of students. Moscow: Moscow State Pedagogical University.

Kovaleva, N.B. (2014). Psycho-pedagogical Conditions of Translation of the Value of Education and the Development of Individual Educational Trajectory in Teenagers. Psychological Science and Education, 19(4), 64-71.

Kovaleva, N.B. (2015). Innovative designing of educational technologies (in aspect of implementation of FGOS of the general education). Moscow: GAOU VO MIOO Publ.

Kovaleva, N.B. (2015a). Story-activity technologies in media education. Moscow: MSPU.

Kovaleva, N.B. (2015b). The Role of Reflection in the Development of a Culture of Collective Creativity. Azimuth of Scientific Research: Pedagogy and Psychology, 4(13), 120-123.

Kovaleva, N.B. (2016a). Text as the Point of Meeting and Misconception. Media Hermeneutics of Self Conceptionsand Images. Pedagogy and education, 3, 238-248. https://doi.org/10.7256/2306434X.2016.3.20043

Kovaleva, N.B. (2016b). The phenomenon of understanding in the media culture. Pedagogy and Psychology of Education, 3, 114-126.

Kovaleva, N.B. (2017). Media Education perspectives of the positively-positional development of the personality and abilities of students. Media Education, 1, 9-25. 
Kovaleva, N.B. (2018). The image of the hero in the representations of the growing generation in the context of the problem of the formation of their identity. Azimuth of Scientific Research: Pedagogy and Psychology, 7(3), 317-321.

Leontev, M.G. (2016). Innovative Approaches in Distance Education in the Field of Environmental Management and Environmental Technologies. MATEC Web of Conferences, 73, 07005. https://doi.org/10.1051/matecconf/20167307005

Leontev, M.G. (2017). Impact of the work in small groups on the educational process in the University of Civil Engineering. MATEC Web of Conferences, 106, 09004. https://doi.org/10.1051/matecconf/201710609004

Leontev, M.G. (2018). Influence of construction organization project managers' personal qualities on their professional efficiency. MATEC Web of Conferences, 193, 05015. https://doi.org/10.1051/matecconf/201819305015

Lomakina, T.Yu. (2015). Research and design of the content of continuing education (theoretical and methodological grounds). Moscow: GAOU VO MIOO Publ.

Markova, A.K., Mathis, A. \& Orlov, A.B. (1990). The formation of learning motivation. Moscow: Master.

Masalimova, A.R., Mikhaylovsky, M.N., Grinenko, A.V., Smirnova, M.E., Andryushchenko, L.B., Kochkina, M.A. \& Kochetkov, I.G. (2019). The interrelation between cognitive styles and copying strategies among student youth. Eurasia Journal of Mathematics, Science and Technology Education, 15(4), em1695. https://doi.org/10.29333/ejmste/103565

Miroshkin, D.V., Grinenko, A.V., Tkhugo, M.M., Mizonova, O.V., Kochetkov, I.G., Kazakova, S.N. \& Miloradova, N.G. (2019). Psychology of ecological consciousness. Ekoloji, 28(107), 593-599.

Mitina, I.D., Vasyakin, B.S., Pozharskaya, E.L., Berezhnaja, M.S. \& Kovaleva, N.B. (2017). The Development of Psychological and Pedagogical Support For The Students' Social And Professional Self-Determination System. Modern Journal of Language Teaching Methods, 7(12), 275-285.

Nesterova, A.A., Babieva, N.S., Grinenko, A.V., Sokolovskaya, I.E., Krasheninnikova, N.A. \& Merenkova, I.V. (2019). The Eco-Psychological Approach: Designing Parent Education and Support Programs in an Inclusive School. Ekoloji, 107, 737-742.

Ponomarev, Y.A. \& Semenov, I.N. (1990). The psychology of creativity: General, differential, applied. Moscow: Science.

Rastiannikov, A.V., Stepanov, S.Yu. \& Ushakov, D.V. (2002). Development of reflexive competence in joint creativity. Moscow: PER SE.

Salakhova, V.B., Belinskaya, D.B., Erofeeva, M.A., Ulyanova I.V., Zotova, L.E., Khammatova, R.S. \& Mizonova, O.V. (2018). Modern methods of diagnosing addiction to psychoactive substances: neurophysiological aspects. Electronic journal of general medicine, 15(6), 94-106. https://doi.org/10.29333/ejgm/100633

Salakhova, V.B., Bulgakov, A.V. Sokolovskaya, I.E., Khammatova, R.S. \& Mikhaylovsky, M.N. (2016). Substantive (Content-Related) Characteristics of Deviant Behavior as a Social and Psychological Phenomenon. International journal of environmental \& science education, 11(17), 10609-10622. URL: http://www.jjese.net/makale/1381

Salakhova, V.B., Oschepkov, A.A., Lipatova, N.V., Popov, P.V. \& Mkrtumova, I.V. (2016a). Features of Social Attitudes and Value Orientations of Youths and Adolescents Prone to Auto-Aggressive Behavior. International journal of environmental \& science education, 11(16), 9017-9025. URL: http://www.ijese.net/makale/1144

Salakhova, V.B., Ovsyanik, O.A., Shmeleva, N.B., Lvova, E.N. \& Shabanova, O.V. (2016b). The Problem of Higher Education in the Executive System of Russian Government. International journal of environmental \& science education, 11(4), 9883-9889. 
Salakhova, V.B., Goloshumova, G.S., Albakova, Z.A.-M., Marchev, K.V. \& Krasheninnikova, N.A. (2019). The interrelation of environmental and social factors and man's mental health. Ekoloji, 2(107), 60136016.

Salakhova, V.B., Lekareva, E.E., Zaretskiy, V.V., Artamonova, E.G., Efimova, O.I. \& Kalinina, N.V. (2018). Comprehensive rehabilitation of minors with deviant and delinquent behavior: The experience of the Russian system of education. Eurasian Journal of Analytical Chemistry, 13(1b), em84. URL: https://doi.org/10.29333/ejac/102249

Semenov, I.N. (2017). Reflexive-developing environment of formation of thinking and self-consciousness of subjects of education. World of psychology, 4, 81-97.

Slobodchikov, V.I. \& Isaev, E.I. (1995). Fundamentals of psychological anthropology. Human psychology: an Introduction to the psychology of subjectivity. Moscow: SHKOLA-Press.

Sokolovskaya, I.E., Grinenko, A.V., Miroshkin, D.V., Udodov, A.G., Egorova, E.V. \& Diatlova, E.V. (2019). The Eco-Psychological Approach in the Psychological Follow-Up Program for Children with Limited Abilities. Ekoloji, 107, 659-664.

Vulfov, B.Z. \& Kharkin V.N. (1995). Pedagogy of reflection. Moscow: Master.

Vygotsky, L.S. (1991). Pedagogical psychology. Moscow: Pedagogy.

Zaretsky, V.K. (2014). Social cognition and mentality in the mirror of the creative problem solving process. Counseling Psychology and Psychotherapy, 4, 207-222. 